Check for updates

Cite this: Chem. Sci., 2019, 10, 5162

¿ All publication charges for this article have been paid for by the Royal Society of Chemistry

Received 19th March 2019

Accepted 15th April 2019

DOI: $10.1039 / c 9 s c 01356 c$

rsc.li/chemical-science

\section{Photocatalytic carbanion generation - benzylation of aliphatic aldehydes to secondary alcohols $\uparrow$}

\author{
Karsten Donabauer, Mitasree Maity, (D) Anna Lucia Berger, Gregory S. Huff, \\ Stefano Crespi (D) and Burkhard König (D) *
}

We present a redox-neutral method for the photocatalytic generation of carbanions. Benzylic carboxylates are photooxidized by single electron transfer; immediate $\mathrm{CO}_{2}$ extrusion and reduction of the in situ formed radical yields a carbanion capable of reacting with aliphatic aldehydes as electrophiles giving the Grignard analogous reaction product.
Photocatalysis is a fast growing field in chemistry, enabling novel transformations previously unattainable under thermal conditions. ${ }^{1}$ The formation of carbon-carbon bonds is at the core of organic synthesis ${ }^{2}$ and many photocatalytic methods have been reported over the last two decades, the majority of which involve the generation of one or more radical species as key intermediates. ${ }^{3}$ In contrast, photocatalytic $\mathrm{C}-\mathrm{C}$ bond formations involving anionic species as key intermediates are rare ${ }^{4}$ although the reaction between a carbanion and a carbon electrophile, e.g. the Grignard reaction, ${ }^{5}$ is the most typical C-C bond forming reaction. Thus, photocatalytic methods to generate und utilize carbanion intermediates are desired in order to expand the limits of photocatalytic transformations from open shell to closed shell reactivity.

Commonly used photocatalysts, however, are only known to transfer a single electron to a substrate at once (SET), forming the corresponding radical and are not able to transfer two electrons in one step to generate the corresponding carbanion. ${ }^{3}$ Thus, the most intuitive way to photocatalytic carbanion generation is by two subsequent SETs, i.e. a consecutive twofold reduction. ${ }^{6}$ There are a few literature examples illustrating the synthetic applicability of this strategy. ${ }^{4 a, b}$ These include the carbanion formation from 1,2-dibromomalonates giving cyclopropanes after addition to electron poor alkenes ${ }^{4 a}$ and the carbanion formation from tetraalkyl ammonium salts followed by their addition to aromatic aldehydes (Scheme 1a). ${ }^{4 b}$ The latter transformation reported by $\mathrm{Yu}$ et al. is especially interesting, as it is similar to the commonly used Grignard reaction. However, this method seems to be limited to aromatic aldehydes.

Institute of Organic Chemistry, Faculty of Chemistry and Pharmacy, University of Regensburg, Universitätsstraße 31, 93053 Regensburg, Germany. E-mail: burkhard. koenig@ur.de

$\dagger$ Electronic supplementary information (ESI) available. CCDC 1884950. For ESI and crystallographic data in CIF or other electronic format see DOI: $10.1039 / \mathrm{c} 9 \mathrm{sc} 01356 \mathrm{c}$
Beside the generation of a carbanion via a consecutive twofold reduction, redox-neutral carbanion formations are proposed in several reports as well, typically by the reduction of a radical intermediate during the regeneration of the photocatalyst. However, this carbanion is in most cases simply protonated $^{7}$ and examples where it is synthetically used are scarce. $^{4 c-i, 8}$ These include the formation of a C-S bond with benzenesulfonothioates as electrophiles ${ }^{4 e}$ and intramolecular ring closures via an $\mathrm{S}_{\mathrm{N}} 2$ reaction (Scheme $1 \mathrm{~b}$ ). ${ }^{4 f-i}$

To the best of our knowledge, there is so far no report for a redox-neutral photocatalytic carbanion generation followed by its intermolecular reaction with an aliphatic aldehyde or ketone as electrophile (Scheme 1c). As mentioned above, aldehydes and ketones are in this regard especially interesting electrophiles, as the corresponding transformation is analogous to the widespread Grignard reaction. Additionally, substituted carbonyl compounds are poor radical traps for an intermolecular radical addition and forming the desired product using established photocatalytic protocols for radical addition to double bonds is generally not successful. ${ }^{9}$ An exception to this is the photocatalytic radical addition enabled by in situ Brønsted acid activation yielding 3-alkoxy alcohols as reaction products reported by Glorius et al. ${ }^{10}$ Mainly aromatic carbonyl compounds could be used as radical traps.

Inspired by the above mentioned reports, we envisioned a photocatalytic cycle, in which a carbanion is formed from readily available carboxylic acids. Here, the in situ formed carboxylate is oxidized to the corresponding radical. This intermediate is prone to $\mathrm{CO}_{2}$ exclusion, forming the carbon centered radical, which may be converted to the corresponding carbanion by SET from the reduced photocatalyst. The desired product is then formed by addition of the carbanion to an aldehyde as electrophile (Scheme 1c). Herein we describe our efforts to realize this catalytic cycle.

With the envisioned photocatalytic cycle in mind, the coupling between phenylacetic acid (1a) and $n$-pentanal (2a) was chosen as model reaction. Compound 1a was selected as 

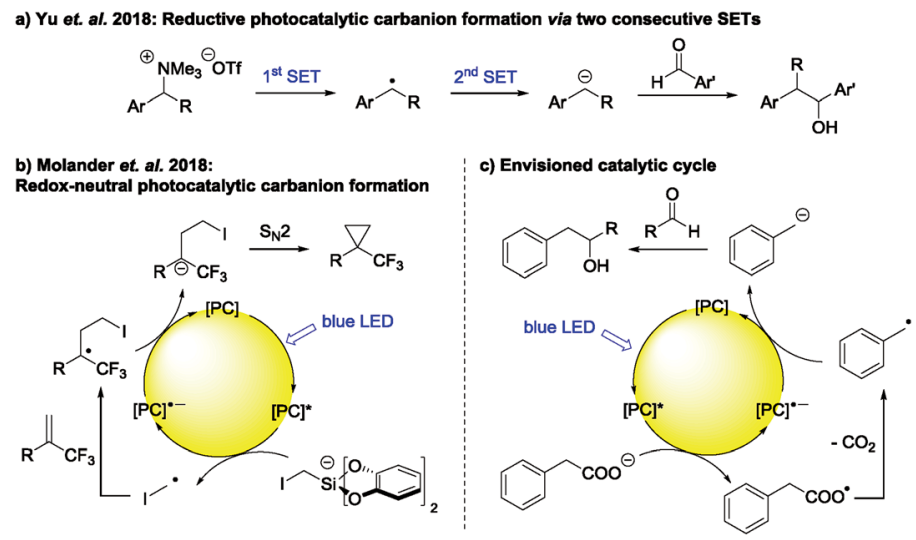

Scheme 1 (a) Photocatalytic carbanion generation via two consecutive SETs. (b) Redox-neutral carbanion generation followed by intramolecular $\mathrm{S}_{\mathrm{N}} 2$ reaction. (c) Envisioned catalytic cycle.

carbanion precursor, since the corresponding benzylic radical as well as the desired carbanion intermediate are stabilized by the aromatic moiety. As the photocatalyst is supposed to engage in a single electron oxidation as well as reduction, employing a catalyst with both a strong oxidation as well as reduction power is crucial. 4CzIPN is an in this regard very attractive organic photocatalyst, exhibiting an excited state redox potential of $E_{1 / 2}\left(\mathrm{P}^{*} / \mathrm{P}^{*-}\right)=+1.35 \mathrm{~V} v$ s. SCE and a ground state reduction potential of $E_{1 / 2}^{\text {red }}\left(\mathrm{P} / \mathrm{P}^{\cdot-}\right)=-1.21 \mathrm{~V} v s$. SCE in MeCN. ${ }^{11}$ With $4 \mathrm{CzIPN}$ as catalyst and $\mathrm{Cs}_{2} \mathrm{CO}_{3}$ as base, the reaction proceeded smoothly yielding the desired addition product $3 a$ in $73 \%$ GCyield after $16 \mathrm{~h}$ (Table 1). Toluene (4a) was observed as a second product in $15 \%$ yield resulting from the reaction with protons as electrophile.

To increase the reaction yield, several parameters were optimized (Table 1, for the full optimization process see ESI $\dagger$ ). A slight improvement could be realized by using DMA as solvent.

Table 1 Optimization of reaction conditions ${ }^{a}$

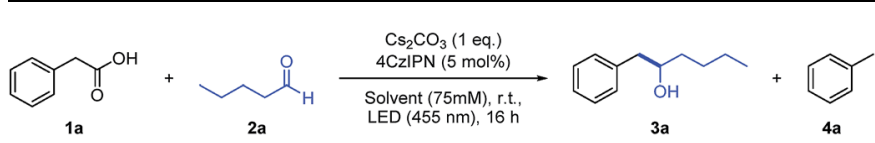

\begin{tabular}{lllll}
\hline Entry & Solvent & Additive (eq.) & ${\text { Yield } 3 \mathbf{a}^{b}[\%]}$ & ${\text { Yield } \mathbf{4 a}^{b}[\%]}^{\circ}$ \\
\hline 1 & Dry DMF & - & 73 & 15 \\
2 & Dry DMA & - & 75 & 11 \\
3 & DMA & - & $75(63)^{c}$ & $\mathbf{1 2}$ \\
4 & DMA & $\mathrm{H}_{2} \mathrm{O}(3$ eq.) & 34 & 55 \\
$5^{d}$ & DMA & - & Not detected (n.d.) & n.d. \\
$6^{e}$ & DMA & - & n.d. & n.d. \\
$7^{f}$ & DMA & - & n.d. & n.d. \\
$8^{g}$ & DMA & - & $64(48)^{c}$ & 12
\end{tabular}

${ }^{a}$ Reactions were performed with $1 \mathrm{a}(150 \mu \mathrm{mol}, 1$ eq.), 2a (3 eq.) and $\mathrm{Cs}_{2} \mathrm{CO}_{3}$ (1 eq.) in degassed solvent $(2 \mathrm{~mL})$ under a nitrogen atmosphere. ${ }^{b}$ GC-yield determined with $n$-decane as internal standard. ${ }^{c}$ Isolated yield in parentheses. ${ }^{d}$ Reaction performed in absence of 4 CzIPN. ${ }^{e}$ Reaction performed in the dark. ${ }^{f}$ Reaction preformed without base. ${ }^{g}$ The preformed $\mathrm{NBu}_{4}^{+}$carboxylate salt $\left(\mathrm{NBu}_{4} \mathrm{PA}, 5\right)$ was used instead of $\mathbf{1 a}$ in absence of $\mathrm{Cs}_{2} \mathrm{CO}_{3}$.
Interestingly, prior drying of the solvent over $4 \AA$ molecular sieve did not improve the yield significantly (entries 2 and 3 ), whereas the addition of $\mathrm{H}_{2} \mathrm{O}$ gave more toluene (4a) (entry 4). Control experiments confirmed that photocatalyst, light and base (entries 5-7) are necessary for the reaction conversion. However, the reaction can be performed in absence of base when using the preformed $\mathrm{NBu}_{4}{ }^{+}$carboxylate salt (5) (entry 8), suggesting that the base merely serves to generate the carboxylate.

The reaction proceeds with various carboxylic acids (Table 2) as carbanion precursors in moderate to good yields. Halogen or $-\mathrm{CF}_{3}$ substituted phenyl acetic acid derivatives give the desired products (3b-h). The presence of an additional methyl or phenyl group on the aromatic ring (3i-1), extended aromatic systems $(3 \mathbf{m}-\mathbf{n})$, a Boc-protected amine (3o) and methoxy (3p-r) functional groups or additional substituents on the benzylic carbon $(3 \mathbf{t}-\mathbf{v})$ are tolerated.

The presence of a stabilizing aromatic moiety is necessary. Aliphatic and allylic carboxylic acids yield only traces of the desired product or none at all.

Aliphatic aldehydes bearing short or long chains (3z-ab) react well as electrophiles. The presence of an additional methyl group at the $\alpha$-carbon decreased the yield to $25 \%$ (3ac) and only traces of the product could be observed when pivalaldehyde was employed (3ad). Substituents in the $\beta$-position (3ae) are tolerated and even adding a second methyl group showed only a minor effect (3af). Aromatic aldehydes, e.g. benzaldehyde (2i), gave the corresponding product as well, but a radical-radical cross coupling of the benzyl radical and the ketyl radical similar to our previous report ${ }^{12}$ instead of a carbanion generation cannot be excluded (Section 8, ESI $\dagger$ ).

The formation of byproducts was investigated for selected

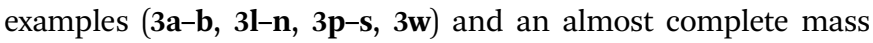
balance could be obtained in most cases when combining the yield of the desired (3) and the decarboxylated (4) product (Table 2). If this was not the case, e.g. for $\mathbf{3 p}$, an incomplete conversion of $\mathbf{1}$ was observed. Ketones, e.g. acetone (6), yield only small amounts of the tertiary alcohol (Table S9, ESI†). Using acetone (6) as co-solvent (1:1 mixture of DMA and acetone) increased the yield and $3 a g$ could be isolated in $32 \%$ (Table 2). 
Table 2 Scope of the reaction ${ }^{a}$

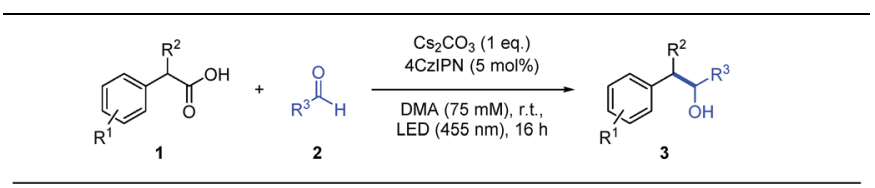

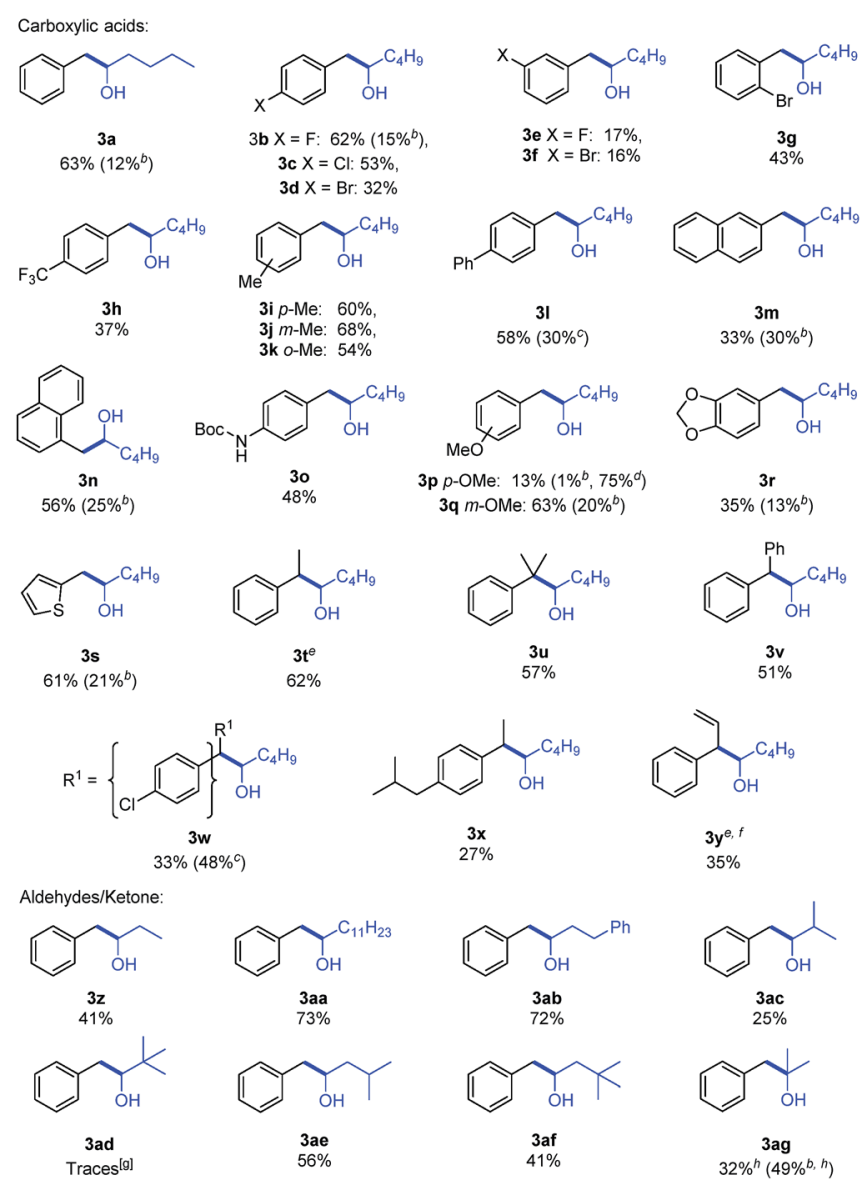

${ }^{a}$ Reactions were performed with 1 (150 $\mu$ mol, 1 eq.) and 2 (3 eq.) in degassed DMA $(2 \mathrm{~mL})$ under a nitrogen atmosphere. If not noted otherwise, the numbers indicate isolated yields. ${ }^{b}$ GC-yield of the corresponding decarboxylated side-product $\mathbf{4}$ determined by GC-FID analysis with $n$-decane as internal standard. ${ }^{c}$ Isolated yield of the corresponding decarboxylated side-product $4 .{ }^{d}$ Recovered starting material 1 after complete reaction time. ${ }^{e}$ Mixture of syn- and antiproduct was obtained. ${ }^{f}$ trans-Styrylacetic acid rather than $\alpha$ vinylphenylacetic acid was used as starting material. ${ }^{g}$ Observed by GC-MS, not isolated. ${ }^{h}$ Acetone/DMA (1:1) was used as solvent.

Further, several electrophiles for an intermolecular $\mathrm{S}_{\mathrm{N}} 2$ reaction were tested (Table $\mathrm{S} 11$, ESI $\dagger$ ), however an efficient system could not be found and only product traces were detected in some cases.

Starting the mechanistic investigation, a photo-conversion of $4 \mathrm{CzIPN}$ was observed during the course of the reaction (Fig. S1, ESI $\dagger$ ). The degradation product could be isolated and identified as $4 \mathrm{CzBnBN}$ (7a) by X-ray crystal structure analysis (Scheme 2). Compound $7 \mathbf{a}$ is likely formed by radical addition of the benzyl radical to the radical anion of $4 \mathrm{CzIPN}$, followed by cyanide elimination similar to reactions reported by different groups. ${ }^{13}$
4CzBnBN seems to be significantly more photo-stable and the product resulting from a second cyanide elimination could only be detected in traces. Performing the benzylation reaction with $4 \mathrm{CzBnBN}$ as catalyst gave the desired product as well (Scheme $\mathrm{S} 4$, ESI $\dagger$ ), showing that $4 \mathrm{CzBnBN}$ is contributing and likely the main active catalyst for the carbanion formation. Ground state potentials of $E_{1 / 2}^{\mathrm{ox}}\left(\mathrm{P}^{\cdot+} / \mathrm{P}\right)=+1.48 \mathrm{~V}$ vs. $\mathrm{SCE}$ and $E_{1 / 2}^{\mathrm{red}}\left(\mathrm{P} / \mathrm{P}^{\cdot-}\right)=$ $-1.72 \mathrm{~V} v s$. SCE in DMF were measured by CV.

The first step in our mechanistic hypothesis is the oxidation of the carboxylate followed by the extrusion of $\mathrm{CO}_{2}$ to generate a benzyl radical. There are several reports describing this process with various photoredox catalysts. ${ }^{14}$ Accordingly, the emission of $4 \mathrm{CzBnBN}$ could be quenched upon addition of $\mathrm{NBu}_{4} \mathrm{PA}(5)$ resulting in a linear Stern-Volmer plot (Fig. S7, $\left.\mathrm{ESI}^{\dagger}\right)$, confirming the interaction between the excited photocatalyst and the substrate. The following $\mathrm{CO}_{2}$ elimination could be monitored by in situ IR spectroscopy (Fig. 1) together with the depletion of the aldehyde in course of the reaction.

Next, deuterium labeling experiments were conducted to support the formation of an anionic intermediate during the later course of the reaction (Scheme $3 \mathrm{a}$ ). With $\mathrm{D}_{2} \mathrm{O}$ as electrophile, the corresponding deuterated decarboxylated starting material was isolated $(\mathbf{4 v}-\boldsymbol{d})$. As a control experiment, the nondeuterated product $(\mathbf{4 v})$ was obtained when the reaction was performed in deuterated DMF in absence of $\mathrm{D}_{2} \mathrm{O}$. Addition of $\mathrm{D}_{2} \mathrm{O}$ to a reaction mixture after completed irradiation did not yield any $\mathbf{4 v}$ - $\boldsymbol{d}$ from $4 \mathbf{v}$ via base-induced $\left(\mathrm{Cs}_{2} \mathrm{CO}_{3}\right) \mathrm{H} / \mathrm{D}$-exchange (Scheme S5, ESI $\dagger$ ).

In addition to the incorporation of deuterium, a carbanion intermediate is expected to engage in an E1cb elimination if an appropriate leaving group is present in the homobenzylic position. Hence, tropic acid (9) was subjected to the reaction conditions (Scheme $3 \mathrm{~b}$ ). Indeed, styrene (10) together with the decarboxylated byproduct (11) was detected. To exclude styrene formation from $\mathbf{1 1}$ by a simple $\mathrm{E} 2$ elimination induced by $\mathrm{Cs}_{2} \mathrm{CO}_{3}, 11$ was directly subjected to the applied reaction conditions, yielding no styrene (Scheme S6, ESI $\dagger$ ).

In order to thoroughly study the feasibility and selectivity of the addition of the benzyl anion (15) to the electrophile, a computational analysis was performed. The $\mathrm{C}=\mathrm{O}$ addition and the acid-base reaction of $\mathbf{1 5}$ and the $\mathrm{C}_{\alpha}-\mathrm{H}$ was proven at the SMD(DMF)- $\omega$ B97X-D/TZVP level of theory (see Section 7.9 in the $\mathrm{ESI} \dagger$ ). Indeed, the reaction of the benzyl anion with the aldehydes results to be exothermal $\left(\Delta G=-6.9 \mathrm{kcal} \mathrm{mol}^{-1}\right)$ and slightly kinetically favored $\left(\Delta G^{*}=+6.2 \mathrm{kcal} \mathrm{mol}^{-1}\right)$ compared to the abstraction of the acidic proton in the $\alpha$ position $\left(\Delta G^{*}=\right.$ $+6.8 \mathrm{kcal} \mathrm{mol}^{-1}$ ). Ketones were found to be less selective towards the $\mathrm{C}=\mathrm{O}$ addition of the benzyl anion compared to the aldehydes (see compound $\mathbf{3 a g}$ ). As a parallelism, the reaction of the benzyl anion with the ketonic $\mathrm{C}=\mathrm{O}$ is almost thermoneutral $\left(\Delta G=+1.5 \mathrm{kcal} \mathrm{mol}^{-1}\right)$. The competing acid-base reaction is exothermal $\left(\Delta G=-12.1 \mathrm{kcal} \mathrm{mol}^{-1}\right)$, with comparable barriers $\left(\Delta G^{*} \mathrm{ca} .10 \mathrm{kcal} \mathrm{mol}^{-1}\right)$. The barriers for the reactions of 15 with DMA are higher compared to the ones of aldehydes and ketones.

Considering the experimental observations, computational results and cited literature reports, the following mechanism is 

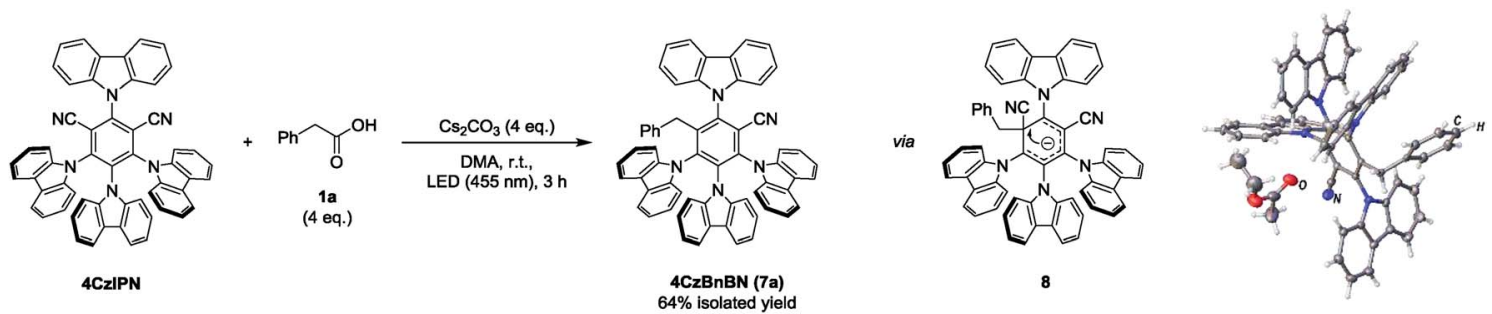

Scheme 2 Isolation of 4 CzIPN photo-conversion product 4CzBnBN (7a). The reaction was performed with 4 CzIPN (30 $\mu$ mol, 1 eq.) and 1a (4 eq.) in degassed DMA (2 $\mathrm{mL})$ under a nitrogen atmosphere.
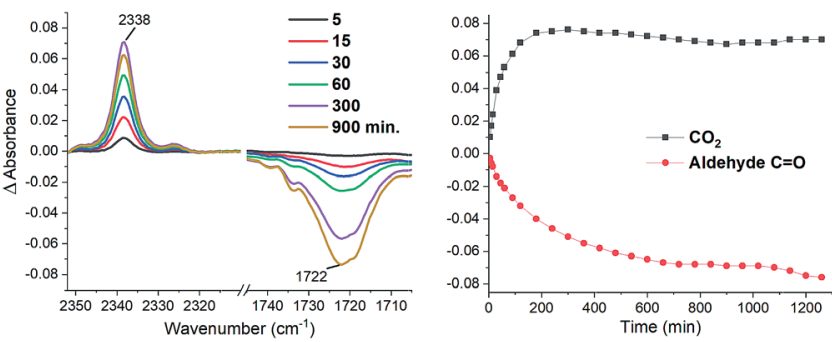

Fig. 1 In situ FT-IR studies. Irradiation of a solution containing $\mathrm{NBu}_{4} \mathrm{PA}$ (5) $(75 \mathrm{mM}), 2 \mathrm{a}(75 \mathrm{mM})$ and $4 \mathrm{CzBnBN}(3.75 \mathrm{mM})$ in dry DMA lead to the formation of $\mathrm{CO}_{2}\left(2338 \mathrm{~cm}^{-1}\right)$ and the depletion of $2 \mathrm{a}\left(1722 \mathrm{~cm}^{-1}\right)$.

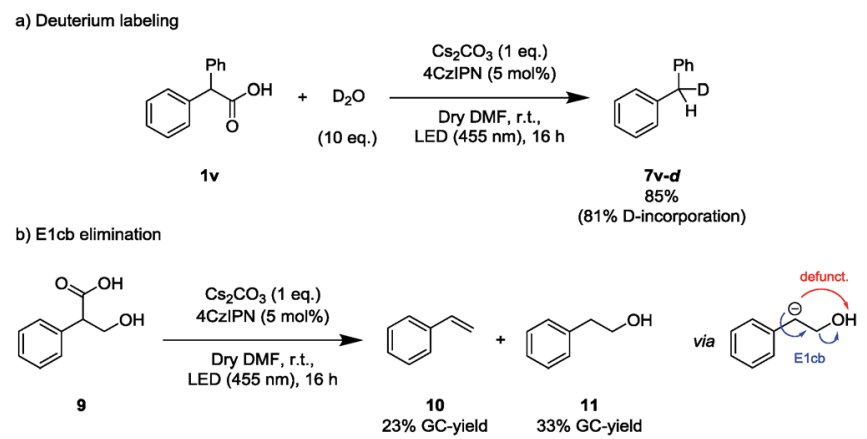

Scheme 3 Experiments supporting the formation of a reactive anionic intermediate.

proposed (Scheme 4): the carboxylic acid $\mathbf{1}$ is deprotonated by the base $\left(\mathrm{Cs}_{2} \mathrm{CO}_{3}\right)$ to give carboxylate 12. The carboxylate $\left(E_{1 / 2}^{\mathrm{OX}}\left(\mathrm{NBu}_{4} \mathrm{PA} 5\right)=+1.27 v s . \mathrm{SCE}^{14 a}\right)$ can be oxidized by the

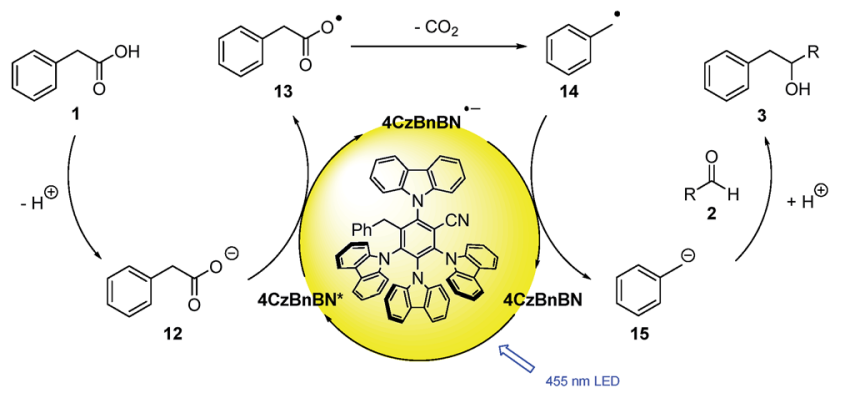

Scheme 4 Proposed mechanism. excited photocatalyst $4 \mathrm{CzBnBN}\left(E_{1 / 2}^{\mathrm{ox}}\left(\mathrm{P}^{*} / \mathrm{P}^{\cdot-}\right)=+1.21 \mathrm{~V} v s\right.$. SCE $)$ and the generated radical species $\mathbf{1 3}$ is transformed to the benzylic radical 14 by elimination of $\mathrm{CO}_{2}$. The radical anion of 4 CzBnBN is with a reduction potential of $E_{1 / 2}^{\text {red }}\left(\mathrm{P} / \mathrm{P}^{\cdot-}\right)=-1.72 \mathrm{~V}$ vs. SCE not able to reduce aliphatic aldehydes $\left(E_{1 / 2}^{\mathrm{red}}(3\right.$-methylbutanal $2 \mathrm{~g})=-2.24 \mathrm{~V}$ vs. $\left.\mathrm{SCE}^{15}\right)$ and hence transfers an electron to the more easily reducible benzyl radical $\left(E_{1 / 2}^{\mathrm{red}}=-1.43 \mathrm{~V} v\right.$ s. $\left.\mathrm{SCE}^{16}\right)$ to form carbanion 15. This species is capable of adding to aldehydes (2) forming the desired product 3 after protonation of the alcoholate.

\section{Conclusions}

In summary, a redox-neutral procedure to benzylate aliphatic aldehydes via the photocatalytic generation of a carbanion intermediate is presented, rendering the desired Grignard analogous products in moderate to good yields. The proposed mechanism is supported by emission quenching, in situ UV/VIS and in situ IR studies, while the presence of the reactive anionic intermediate is shown by deuterium labeling, E1cb elimination and DFT calculation.

\section{Conflicts of interest}

There are no conflicts to declare.

\section{Acknowledgements}

This work was supported by the German Science Foundation (DFG, KO 1537/18-1). This project has received funding from the European Research Council (ERC) under the European Union's Horizon 2020 Research and Innovation Programme (grant agreement No. 741623). We thank Dr Rudolf Vasold for GC-MS measurements, Nele Berg for in situ NMR-measurements, the XRay department for crystal structure analysis and Regina Hoheisel for CV measurements.

\section{Notes and references}

1 M. H. Shaw, J. Twilton and D. W. MacMillan, J. Org. Chem., 2016, 81, 6898-6926.

2 G. Brahmachari, RSC Adv., 2016, 6, 64676-64725.

3 (a) D. Ravelli, S. Protti and M. Fagnoni, Chem. Rev., 2016, 116, 9850-9913; (b) J. Twilton, C. Le, P. Zhang, M. H. Shaw, R. W. Evans and D. W. C. MacMillan, Nat. Rev. Chem., 
2017, 1, 0052; (c) C. K. Prier, D. A. Rankic and D. W. MacMillan, Chem. Rev., 2013, 113, 5322-5363; (d) N. A. Romero and D. A. Nicewicz, Chem. Rev., 2016, 116, 10075-10166; (e) L. Marzo, S. K. Pagire, O. Reiser and B. König, Angew. Chem., Int. Ed., 2018, 57, 10034-10072; $(f)$ I. Ghosh, L. Marzo, A. Das, R. Shaikh and B. König, Acc. Chem. Res., 2016, 49, 1566-1577.

4 (a) Y. Zhang, R. Qian, X. Zheng, Y. Zeng, J. Sun, Y. Chen, A. Ding and H. Guo, Chem. Commun., 2015, 51, 54-57; (b) L. L. Liao, G. M. Cao, J. H. Ye, G. Q. Sun, W. J. Zhou, Y. Y. Gui, S. S. Yan, G. Shen and D. G. Yu, J. Am. Chem. Soc., 2018, 140, 17338-17342; (c) Y. Kumagai, T. Naoe, K. Nishikawa, K. Osaka, T. Morita and Y. Yoshimi, Aust. J. Chem., 2015, 68, 1668; (d) V. R. Yatham, Y. Shen and R. Martin, Angew. Chem., Int. Ed., 2017, 56, 10915-10919; (e) W. Kong, H. An and Q. Song, Chem. Commun., 2017, 53, 8968-8971; (f) J. P. Phelan, S. B. Lang, J. S. Compton, C. B. Kelly, R. Dykstra, O. Gutierrez and G. A. Molander, J. Am. Chem. Soc., 2018, 140, 8037-8047; (g) J. A. Milligan, J. P. Phelan, V. C. Polites, C. B. Kelly and G. A. Molander, Org. Lett., 2018, 20, 6840-6844; (h) C. Shu, R. S. Mega, B. J. Andreassen, A. Noble and V. K. Aggarwal, Angew. Chem., Int. Ed., 2018, 57, 15430-15434; (i) C. Shu, A. Noble and V. K. Aggarwal, Angew. Chem., Int. Ed., 2019, 58, 38703874 .

5 (a) V. Grignard, C. R. Acad. Sci., 1900, 130, 1322-1324; (b) G. S. Silverman and P. E. Rakita, Handbook of Grignard Reagents, Marcel Dekker, Inc., New York, 1996.

6 (a) K. Hironaka, S. Fukuzumi and T. Tanaka, J. Chem. Soc., Perkin Trans. 2, 1984, 1705-1709; (b) J.-M. Kern and J.-P. Sauvage, J. Chem. Soc., Chem. Commun., 1987, 546-548; (c) D. Li, C.-M. Che, H.-L. Kwong and V. W.-W. Yam, J. Chem. Soc., Dalton Trans., 1992, 3325-3329.

7 (a) H. Yokoi, T. Nakano, W. Fujita, K. Ishiguro and Y. Sawaki, J. Am. Chem. Soc., 1998, 120, 12453-12458; (b) H. Huang, C. Yu, Y. Zhang, Y. Zhang, P. S. Mariano and W. Wang, J. Am. Chem. Soc., 2017, 139, 9799-9802; (c) Y. Yasu, T. Koike and M. Akita, Adv. Synth. Catal., 2012, 354, 3414-3420; (d)
A. J. Musacchio, L. Q. Nguyen, G. H. Beard and R. R. Knowles, J. Am. Chem. Soc., 2014, 136, 12217-12220; (e) R. Zhou, H. Liu, H. Tao, X. Yu and J. Wu, Chem. Sci., 2017, 8, 4654-4659; (f) A. Gualandi, D. Mazzarella, A. Ortega-Martínez, L. Mengozzi, F. Calcinelli, E. Matteucci, F. Monti, N. Armaroli, L. Sambri and P. G. Cozzi, ACS Catal., 2017, 7, 5357-5362; (g) X. Dong, P. Hu, W. Shen, Z. Li, R. Liu and X. Liu, Polymers, 2017, 9, 400; (h) A. Noble, R. S. Mega, D. Pflasterer, E. L. Myers and V. K. Aggarwal, Angew. Chem., Int. Ed., 2018, 57, 2155-2159.

8 S. B. Lang, R. J. Wiles, C. B. Kelly and G. A. Molander, Angew. Chem., Int. Ed., 2017, 56, 15073-15077.

9 (a) A. Clerici, O. Porta and P. Zago, Tetrahedron, 1986, 42, 561-572; (b) A. Clerici and O. Porta, J. Org. Chem., 1989, 54, 3872-3878; (c) S. Wilsey, P. Dowd and K. N. Houk, J. Org. Chem., 1999, 64, 8801-8811; (d) C. Che, Z. Qian, M. Wu, Y. Zhao and G. Zhu, J. Org. Chem., 2018, 83, 5665-5673.

10 L. Pitzer, F. Sandfort, F. Strieth-Kalthoff and F. Glorius, J. Am. Chem. Soc., 2017, 139, 13652-13655.

11 J. Luo and J. Zhang, ACS Catal., 2016, 6, 873-877.

12 A. L. Berger, K. Donabauer and B. König, Chem. Sci., 2018, 9, 7230-7235.

13 (a) T. Itou, Y. Yoshimi, T. Morita, Y. Tokunaga and M. Hatanaka, Tetrahedron, 2009, 65, 263-269; (b) M. T. Pirnot, D. A. Rankic, D. B. Martin and D. W. MacMillan, Science, 2013, 339, 1593-1596.

14 (a) L. Capaldo, L. Buzzetti, D. Merli, M. Fagnoni and D. Ravelli, J. Org. Chem., 2016, 81, 7102-7109; (b) T. Patra and D. Maiti, Chem.-Eur. J., 2017, 23, 7382-7401; (c) J. Schwarz and B. König, Green Chem., 2018, 20, 323-361; (d) H. Huang, X. Li, C. Yu, Y. Zhang, P. S. Mariano and W. Wang, Angew. Chem., Int. Ed., 2017, 56, 1500-1505.

15 D. Nicewicz, H. Roth and N. Romero, Synlett, 2015, 27, 714723.

16 (a) B. A. Sim, D. Griller and D. D. M. Wayner, J. Am. Chem. Soc., 1989, 111, 754-755; (b) D. D. M. Wayner, D. J. McPhee and D. Griller, J. Am. Chem. Soc., 1988, 110, 132-137. 